\title{
The value of radiographs in the management of the fractured nose
}

\author{
A. NIGAM*, A. GONI*, A. BENJAMIN ${ }^{+} \&$ A. R. \\ DASGUPTA* \\ Departments of ${ }^{*}$ Otolaryngology and ${ }^{+}$Accident and Emergency, Manor Hospital, \\ Walsall
}

\section{SUMMARY}

Over a 6-month period a record was kept of all patients presenting to the accident and emergency (A\&E) department with nasal injuries. The results of the nasal radiographs were analysed to gauge their benefit. It was found that there was poor correlation between the radiological findings and the presence of external deformity, the latter determining the decision to carry out treatment. Routine radiographs of the nose are unnecessary in patients with nasal trauma.

\section{INTRODUCTION}

Patients presenting to the $A \& E$ department with injuries to the face and nose are examined initially by the duty doctor to exclude, amongst other things, the presence of a septal haematoma. The examining doctor may then decide at his discretion whether or not to carry out a radiological examination. The decision to take radiographs of the nose may be taken in the belief that the detection of a fracture, as in other sites may influence further management, or that it might have medico-legal significance. A proportion of patients are then requested to attend the ear, nose and throat (ENT) clinic for further opinion and management. Depending upon the nature of injury and deformity, some of these referred patients subsequently undergo manipulation of the fractured nose under general anaesthetic.

This study was carried out to determine the value of routine radiography in patients with mild to moderate injuries of the nose. 


\section{METHODS}

Over a 6-month period a careful record was kept of all patients presenting with injuries of the nose to the A\&E Department at Manor Hospital. No guidelines exist, but patients with visible bruising/deformity or those presenting after assault, had standard radiographs of the nose taken in both occipito-mental and lateral views. The radiological examination was carried out immediately, except in patients presenting late at night who were requested to return the following morning. A note was made of the radiograph report to assess the presence of a fracture of the nasal bones. Those patients with clinically obvious deformity, or fractures suspected by the $A \& E$ officer after radiological examination were referred to the next available ENT out-patients clinic. There they were assessed and those with significant cosmetic deformity, were treated by carrying out a closed manipulation of the nose under general anaesthetic within 5 to 14 days of the injury occurring. The factor determining treatment of the patient was essentially cosmetic deformity and no importance was given by the ENT surgeons to the presence, or indeed absence, of a fracture on X-ray film.

The results were analysed to determine the specificity and sensitivity. $J$-value (Taube 1986) was determined by the formula:

$$
J=\text { specificity }+ \text { sensitivity }-1 .
$$

\section{RESULTS}

In all 246 patients who presented to A\&E with nasal injuries 194 were referred for radiological examination (Table 1). Of these, 24 did not undergo radiological examination because: (1) 18 patients did not return to A\&E the following morning as requested; (2) three patients were pregnant; and (3) three patients refused to have a radiological examination.

Table 1. Number of patients with nasal fracture presenting to A\&E

\begin{tabular}{lccccc}
\hline $\begin{array}{l}\text { Total no. of radiographs } \\
\text { taken in A\&E } \\
n=170\end{array}$ & $\begin{array}{c}\text { Referred to ENT } \\
n=83\end{array}$ & $\begin{array}{c}\text { Underwent MUA* of } \\
\text { fractured nose } \\
n=30\end{array}$ \\
\hline $\mathrm{F}^{\dagger}$ & $\mathrm{NF}^{\ddagger}$ & $\mathrm{F}$ & $\mathrm{NF}$ & $\mathrm{F}$ & $\mathrm{NF}$ \\
\hline 81 & 89 & 67 & 16 & 19 & 11 \\
\hline
\end{tabular}

* Manipulation under general anaesthetic, ${ }^{\dagger}$ fracture, ${ }^{\ddagger}$ no fracture.

\section{DISCUSSION}

There are many variations in the way fractures of the nose are managed. In some $A \& E$ departments fracture line on the nasal septum is displayed at urgent surgery 
and an immediate septoplasty is performed in suitable patients (Murray et al., 1984). In certain hospitals the procedure of closed manipulation is carried out under local anaesthetic (Watson et al., 1988) while a proportion of surgeons prefer to manipulate the fracture under general anaesthetic (Dickson \& Sharpe 1987). Some authors strongly believe that if the radiographs show displacement the nose should be manipulated even if it looks straight (Schultz 1970, Murray \& Maran 1980).

This study demonstrates clearly that at no stage in the management of the patient with nasal trauma did the radiographs serve any useful purpose. The decision to manipulate the nose is made on the external appearance of the nose and it would be no exaggeration to state that in the absence of any consmetic deformity very few surgeons in this country would be willing to manipulate the nose, irrespective of the appearances on radiograph. As the results demonstrate, the presence of a fracture line corresponded with cosmetic deformity in only $11.2 \%$ of patients presenting to $A \& E$ (Table 2). In addition 11 patients $(36 \%)$ undergoing treatment did not have a demonstrable fracture on radiograph (Table 1). Thus, this is an investigation with poor specificity and little sensitivity (Table 2). In order to be useful, a test should show a greater proportion of positive results for the diseased group than for the control. However, as the low J-value indicates, radiographs as a diagnostic test for nasal deformity gave a large proportion of positives for both diseased and control groups. If used as a screening test to detect nasal deformity requiring treatment, a large proportion of patients with deformity would be missed. Conversely, as a screening test, a positive result on radiograph would indicate unnecessary treatment for a significant group of patients with no deformity.

The observation that radiographs of the injured nose are unnecessary is not new. Clayton \& Lesser (1986) studied 54 patients with nasal injuries and concluded that standard radiographs were not useful in their management.

Radiographs of the nasal bones are not easy to interpret. The anatomical variations and the presence of vascular markings make it extremely difficult to detect the presence of a fracture. Of the 87 patients referred to the ENT clinic with a nasal deformity or fracture suspected by the A\&E officer only 67 were reported by the radiologists as having a fracture of the nasal bones.

A significant proportion of nasal injuries may have compound fractures as they are associated with epistaxis, suggesting breach of the nasal mucosa by the fractured segment. However, compound fractures of the nose do not carry the grave implications seen in compound fractures elsewhere, and after suture of the skin if breached, are treated in exactly the same manner as simple fractures.

A popular argument in favour of radiographs is given as 'medico-legal reasons'. One of the leading medical defence societies has confirmed that if an investigation

Table 2. Rates of cosmetic deformity in patients presenting to $A \& E$

\begin{tabular}{lcrr}
\hline & Deformity present & No deformity & Total \\
\hline fracture on radiograph & 19 & 62 & 81 \\
No fracture on radiograph & 11 & 78 & 89 \\
Total & 30 & 140 & 170 \\
\hline
\end{tabular}

Sensitivity, $63.3 \%$; specificity, $55.7 \%$; and $J$ value, 0.19 . 
is not necessary for the clinical management of the patient it need not be performed. It could be argued that the presence of a fracture might influence the legal significance of an injury and may be of some interest to the police in cases of assault. Apart from the difficulty in being certain about the presence of a fracture on radiograph, it is debatable whether it is wise to spend limited, and now keenly $\bar{c}$ audited, hospital resources in performing an investigation routinely which does $\frac{\overline{\bar{N}}}{\overline{0}}$ not materially affect the clinical outcome of the patient's illness. The cost of a $\frac{\pi}{\vec{\nabla}}$ radiograph of the nose $(£ 6-25)$ is minimal when considered singularly but is

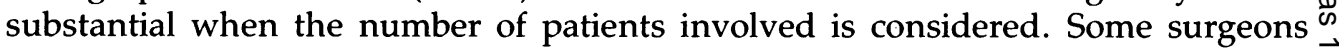
may feel that providing radiological evidence to assist potential victims of assault in court is part of the service the NHS should provide. In these circumstances it $\vec{\omega}$ would be quite logical to perform radiographs in selected patients, depending on $\frac{\odot}{\odot}$ the source of injury and the surgeons' personal belifefs. A system where the police $\underline{3}$. could request radiographs of nasal bones in people reporting to them after assault $\overrightarrow{0}$

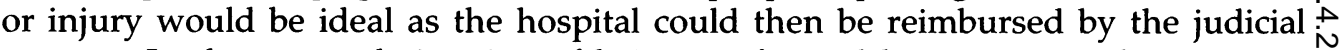
process. In the unusual situation of being confronted by a patient who presents $\stackrel{\oplus}{\oplus}$ frequently with a nasal injury, or one who insists there is a cosmetic deformity 9 while the surgeon cannot identify any, a photograph may be of more use than $\vec{\nabla}$ a radiograph as potentially relevant evidence in the event of future litigation.

\section{CONCLUSION}

The decision to manipulate deformities following nasal injuries is taken on clinicat grounds. Fractures of the nose are not necessarily accompanied by external deformities, nor does a deformed nose invariably display a fracture line on radiology. It is therefore unnecessary to carry out radiographs of the nose in patients presenting $\stackrel{D}{2}$ with nasal trauma. The suggestion that radiographs are necessary for medico-legal $\overrightarrow{0}$ purposes is a myth, and clinical photographs of the patients nose are suggested as a more useful alternative for the cautious surgeon.

\section{ACKNOWLEDGEMENTS}

We would like to express our gratitude to Mr D. M. East for allowing us to include his patients in our study, and Dr P. C. Carpenter, Consultant Radiologist and Mr M. J. Merlin, Consultant in A\&E for their assistance in carrying out this project.

\section{REFERENCES}

Clayton M. I. \& Lesser T. H. J. (1986) The role of radiography in the management of nasal fractures. Journal of Laryngology and Otology 100, 797-801.

Dickson M. G. \& Sharpe D. I. (1986) Prospective study of nasal fractures. Journal of Laryngology and 
Otology 100, 543-551.

Murray J. A. M. \& Maran A. G. D. (1980) The treatment of nasal injuries by manipulation. Journal of Laryngology and Otology 94, 1405-1410.

Murray J. A. M., Maran A. G. D., MacKenzie I. J. \& Raab G. (1984) Open v closed reduction of the fractured nose. Archives of Otolaryngology 110, 797-802.

Taube A. (1986) Sensitivity, specificity and predicitive values: a graphical approach. Statistics in Medicine 5, 585-591.

Watson D. J., Parker A. J., Slack R. W. T. \& Griffiths M. V. (1988) Local versus general anaesthetic in the management of the fractured nose. Clinical Otolaryngology 13, 419-494. 